\title{
Portal Hypertensive Colopathy
}

\author{
Vatsala Misra, Vishal Dhingra, S P Misra and Manisha Dwivedi \\ MLN Medical College, Allahabad, \\ India
}

\section{Introduction}

The portal vein drains blood from the small and large intestines, stomach, spleen, pancreas, and gallbladder. The superior mesenteric vein and the splenic vein unite behind the neck of the pancreas to form the portal vein. Normal portal pressure is generally defined between 5 and $10 \mathrm{~mm} \mathrm{Hg}$. An increase in the blood pressure to $12 \mathrm{~mm} \mathrm{Hg}$ or greater, within a system of veins is called portal hypertension (PHT). The most common cause of portal hypertension is cirrhosis of the liver. Other causes include portal vein thrombosis and a parasitic infection by Schistosomiasis. Sometimes the cause is unknown.

Portal hypertension leads to hemodynamic disturbances throughout the gastrointestinal tract. McCormack et al (1985) coined the term congestive gastropathy to represent the mucosal changes in gastric mucosa of patients with portal hypertension and distinguished it histologically from inflammatory gastritis. (McCormack et al., 1985) The entity was attributed to alteration in gastric microcirculation.( Sarfeh et al., 1987 \& Tarnawaski et al., 1988).Initial reports mainly focused on portal hypertensive gastropathy which demonstrated endoscopic and histologic changes seen in the gastric mucosa.(Baxter \& Dobbs, 1988; Corbishley et al.,1988; Foster et al.,1989; SP Misra et al., 1990; Papazian et al., 1986 \& Triger \& Hosking,1989)The entity was renamed as 'portal hypertensive intestinal vasculopathy' with the evidence of small intestinal and colonic involvement. (Kozarek et al., 1991; Thiruvengadam \& Gostout, 1989 \& Viggiano \& Gostout, 1992). The term portal hypertensive colopathy was initially described in the 1990, as a poorly defined entity by Naveau et al. (1991)

In patients with liver cirrhosis and portal hypertension, vascular changes in upper gastrointestinal tract in the form of varices of the esophagus, stomach and portal hypertensive gastropathy and enteropathy are well described. (V Misra et al., 1997, 1998 \& SP Misra et al., 1990). In present chapter various aspects of changes in colonic mucosa of the patients with portal hypertension are described in detail.

\section{Colonoscopy}

Initially some authors have described hemorrhoids and colorectal hypervascularity in patients with portal hypertension (Britton,1963; Hosking et al., 1989 \& Jacobs, 1980) followed by hemorrhage from lower G.I. tract (Herman et al., 1993;Izsak \& Finlay,1980; Weinshel et al., 1986 ). The reported prevalence of hemorrhoid and anorectal varices varied from $25.2 \%$ to $63 \%$ (Britton, 1963;Hosking et al., 1989 \& Jacobs, 1980) and $0 \%$ to 89.3\%(Chawala \& Dilawari, 1991 \& Rabinovitz et al., 1990). 
None of these studies were planned or had control population. We planned a study (SP Misra et al., 1996) to find out the prevalence and factor influencing hemorrhoid, anorectal varices and colopathy. The study included 70 patients with cirrhosis and portal hypertension and 70 controls. A full length colonoscopy was carried out in all cases and presence of hemorrhoids, anorectal varices and colopathy was noted. Hemorrhoids and anorectal varices were noted in $36 \%$ and $40 \%$ patients as compared to $40 \%$ and $0 \%$ in controls respectively. The difference was statistically significant for anorectal varices( $\mathrm{P}$ $<0.001$ ). No correlation to severity of cirrhosis (Child's grade), oesophageal varices, presence or absence of gastric varices, gastropathy or sclerotherapy treatment was observed. Colopathy was seen in $48.5 \%$ and $3 \%$ of patients and controls respectively and it was seen more frequently in patients with large oesophageal varices as compared to smaller varices $(87 \%$ vs $28.5 \%, P<0.001)$ and more often in those with gastric varices than without it (71\%vs $28.5 \%, \mathrm{P}<0.001)$.

Ghoshal et al.( 2001) reported haemorrhoids in 21.9\% patients with PHT and $16 \%$ controls $(p=n s)$. Colorectal varices were seen in $31.7 \%$ patients with PHT and none of the controls $(\mathrm{p}=0.005)$. Portal colopathy was present in $36.6 \%$ patients with PHT and none of the controls $(\mathrm{p}=0.0005)$. None of the parameters (e.g. aetiology of PHT, Child's class, oesophageal variceal eradication by Endoscopic Sclerotherapy with or without Endoscopic variceal ligation, history of variceal bleeding, grade of oesophageal varices, presence of portal hypertensive gastropathy or gastric varices) predicted the occurrence of colorectal varices and portal hypertensive colopathy. Detection of colorectal varices but not portal hypertensive colopathy was associated with occurrence of hematochezia.

Assuming that PHT may cause the changes all over the gastrointestinal (GI) tract, a number of colonoscopic studies were performed. (Chen et al., 1996; Scandalis et al., 1994 \& Sharma et al., 1995).The colonoscopy revealed vascular ectasias, vascular irregularity, vascular dilatation, solitary red spots, diffuse red spots and hemorrhoids. Portal hypertension produces changes in the colorectal mucosa similar to those seen in the mucosa of upper gastrointestinal tract. Other endoscopic abnormalities mentioned in this setting are anorectal and recto-sigmoid varices, hemorrhoids, multiple vascular ectasia like lesions, and nonspecific inflammatory changes. These changes were classified into four types. Solitary vascular ectasias were found predominantly in the transverse and ascending colon (55\%). Diffuse vascular ectasias were found predominantly in the right side colon (45\%). Redness was found in the overall colon and blue vein in the rectum. (Ito et al., 2005). They observed portal hypertensive colopathy in $23 \%$ of patients in rectosigmoid colon, $11 \%$ in the descending colon, $24 \%$ in the transverse colon, $23 \%$ in the ascending colon and $16 \%$ in the cecum. These complications are a common cause of lower gastrointestinal hemorrhage.

Bresci et al(2006). also studied the colonoscopic changes in patients with portal hypertension. They found colonic varices in $31 \%$ of the patients, portal hypertensive colopathy (PHC; defined as diffuse hyperemia, edema, spider angiomas, and spontaneous bleeding of the colonic mucosa) in $54 \%$, and normal colonic findings in $18 \%$. Colonic varices and PHC were present simultaneously in $27 \%$ of the patients. They concluded that colonic lesions are frequent in cirrhotic patients, but statistical analysis showed that these lesions are not specific for the disease and do not correlate with the etiology and degree of cirrhosis, with the endoscopic treatment of esophageal varices, or with the risk of bleeding from the lower gastrointestinal tract. 


\section{Histopathological changes}

Portal hypertension leads to hemodynamic disturbances throughout the GI tract. Despite several studies describing endoscopic changes, histological changes in gastric mucosa were not studied in detail. In earlier studies the congestion of the mucosal capillaries was described as the common change seen in gastric mucosa of the patients with portal hypertension. (Corbishley et al., 1988; Foster et al., 1989 \& SP Misra et al, 1990). Studies of biopsies from the upper GI tract (stomach, duodenum and jejunum) have recorded predominant changes in the mucosal vessels (venules and capillaries). (Kozarek et al., 1991; Thiruvengadam \& Gostout, 1989 \& Viggiano \& Gostout, 1992). Later on a detailed histomorphometric study of mucosal vascular changes seen in gastric, duodenal and jejunal mucosa showed that irregularity and thickening of the mucosal capillary wall is more specific than only congestion(V Misra et al., 1997, 1998) that can be seen due to artifactual factors also. (Corbishley et al.,1988).Despite well documented colonoscopic features very few studies were there describing histopathological changes, that too in brief.( Eleftheriadis et al., 1993;Naveau et al., 1991 \& Scandalis et al 1994). S P Misra et al (1996) found dilated and congested mucosal capillaries in $42 \%$ of colonic biopsies whereas dilated and thick walled capillaries were seen in $49 \%$.

We did a detailed histomorphometric study of changes in mucosal capillaries in colonic biopsies from 55 patients with portal hypertension and 25 controls. (Misra V et al., 2003). After full length colonoscopy biopsies were taken from caecum, ascending colon, transverse colon, descending colon and rectum. Morphometric assessment of diameter of the capillaries and thickness of the capillary wall was done. Presence and absence of the congestion was also noted. Dilated and congested capillaries, as well as, capillaries with irregular thickening of the wall were seen in significantly higher number of sections from patients than controls. Morphometric assessment also showed a significantly higher diameter and thickness of the capillary wall in sections from patients with portal hypertension than controls. A peculiar feature observed was thick walled dilated capillaries without red blood cells in the lumen that were seen in $46.5 \%$ biopsies (irrespective of site) from patients with portal hypertension as compared to $12 \%$ in controls $(\mathrm{P}<0.025)$. The histological changes had no correlation with the clinical or endoscopic findings except that the thickness of the capillary wall was higher in patients who had undergone endoscopic sclerotherapy as opposed to those who had not received sclerotherapy. Besides vascular changes, other important histological features seen in the biopsies are edema, increased mononuclear cell infiltration and fibromuscular proliferation in lamina propria.

It is very important to differentiate the vascular changes of colopathy with angiodysplasia of the colon which may sometimes lead to massive lower GI bleeding. (Sharma et al., 1995) Lesions of angiodysplasia are fewer, smaller, and less widely distributed as compared to those of portal hypertension, (Naveau et al., 1995) because they are usually formed due to degenerative changes (V Misra et al., 2003) in contrast to PHT where increased venous pressure seems to be the main cause. Besides, the age of the patient (angiodysplasia usually occurs in the elderly), association with cirrhosis and endoscopic appearance may also help in differentiation. Histopathology examination of rectal mucosal lesions in patients with portal hypertension shows dilatation of blood vessels in the mucosa, increased lymphocytes and plasma cells in the lamina propria and edema of the mucosa. 


\section{Prognosis and treatment}

Lower gastrointestinal bleeding, is the major complication of portal hypertensive colopathy. These patients may have occult blood loss or overt hematochezia. In patients with liver cirrhosis as the Child-Pugh class worsens and platelet count decreases, the prevalence of portal hypertensive colopathy increases. A colonoscopic examination in patients with liver cirrhosis is indicated, especially those with worsening Child-Pugh class and/or decreasing platelet count, to prevent complications such as lower gastrointestinal bleeding (Ito et al., 2005). Octreotide is a safe and effective treatment for severe acute bleeding from PHC, especially if the patient is not a candidate for transjugular intrahepatic portosystemic shunt (TIPS) or treatment with a beta-blocker due to the severity of liver disease or haemodynamic instability. Aydede $\mathrm{H}$ et al (2003) studied the effects of octreotide and propranolol on colonic mucosa in rats with portal hypertensive colopathy and showed that the mucosal changes in portal hypertensive colopathy could be corrected by drugs modifying portal blood flow.However, a sufficient reduction of portal pressure by propranolol or other medical treatment may be needed in order to discontinue octreotide infusion without the recurrence of bleeding. (Yoshie et al., 2001) Significant relationship between colorectal varices and liver disease has been reported and colorectal varices is highly appeared in patients with extrahepatic portal obstruction. Such patients have revealed arteriovenous communications at angiogram. In general, colonic resection or transanal ligation should be the first option for treatment of bleeding colonic varices and colonic mucosal lesions. Oesophageal variceal band ligation (SP Misra et al., 2002) or sclerotherapy (SP Misra et al., 1999) does not affect the anorectal varices or portal hypertensive colopathy.

\section{Conclusion}

Thus, portal hypertension is an important factor in the etiology of a relatively new entity portal hypertensive colopathy, and these need to be evaluated as they can be the cause of lower gastrointestinal bleeding, in these patients. Major histopathological changes seen in colonic biopsies of patients with PHT are dilated tortuous mucosal capillaries with irregular wall-thickening, edema of lamina propria and mild chronic inflammatory infiltrate, which does not show any association with clinical and endoscopic features. However, these mucosal changes, if present, should not be overlooked and a report on colonic biopsies from patients with PHT should include comments on these parameters.

\section{References}

Aydede H, Sakarya A, Erhan Y, Kara E, Ilkgul O, Ozdemir N.(2003). Effects of octreotide and propranolol on colonic mucosa in rats with portal hypertensive colopathy. Hepatogastroenterology, Vol. 50, Sept-Oct, pp.1352-1355, (ISSN: 0172-6390).

Baxter, J \& Dobbs, B. (1988). Portal hypertensive gastropathy. J.Gastroenterol. Hepatol., Vol. 3, pp.635-644. (ISSN: 0815-9319).

Bresci, G; Parisi, G \& Capria.(2006) A Clinical relevance of colonic lesions in cirrhotic patients with portal hypertension Endoscopy, Aug., Vol.38, Nos.8, pp.830-835.(ISSN 0013-726X) 
Britton, RC. (1963). Influence of portal-systemic collateral patterns and distribution of varices on results of surgical treatment of bleeding esophageal varices. Surgery, May Vol.53, pp.567-574 (ISSN 0039-6060)

Chawla, Y \& Dilawari, JB.(1991).Anorectal varices--their frequency in cirrhotic and noncirrhotic portal hypertension.Gut, Mar, Vol.32, Nos.3, pp.309-311. (ISSN 0017-5749)

Chen, LS; Lin, HC; Lee, FY; Hou, MC \& Lee SD. (1996). Portal hypertensive colopathy in patients with cirrhosis. Scand. J.Gastroenterol., May, Vol. 31, Nos.5, pp.490-494. (ISSN0036-5521)

Corbishley, CM; Saverymuttu, S\& Maxwell, JD. (1988). Use of endoscopic biopsy for diagnosing congestive gastropathy.J. Clin. Pathol., Nov., Vol. 41, Nos.11, pp.11871190. (ISSN 0021-9746)

Eleftheriadis, E; Kotazampassi, K; Karakavelas, G; Tzioufa, V \& Papadimitriou, K.(1993) Portal hypertensive colopathy: endoscopic, hemodynamic and morphometric study. Digestive Endoscopy, Vol.5, pp.224-230.(ISSN 0915-5635)

Foster, PN; Wyatt, JI; Bullimore, DW\& Losowsky, MS. (1989). Gastric mucosa in patients with portal hypertension: prevalence of capillary dilatation and Campylobacter pylori.J. Clin. Pathol., Sept., Vol. 42, Nos.9, pp.919-921. (ISSN 0021-9746)

Ghoshal, UC; Biswas, PK; Roy, G; Pal, BB; Dhar, K \& Banerjee, PK.(2001). Colonic mucosal changes in portal hypertension. Trop Gastroenterol, Jan-Mar, Vol.22, Nos.1, pp.2527.(ISSN 0250-626X)

Herman, BE; Baum, S; Denobile, J\& Volpe, RJ.(1993). Massive bleeding from rectal varices. Am J Gastroenterol., Jun, Vol.88, Nos.6, pp.939-942.(ISSN 0002-9270)

Hosking, SW; Smart, HL; Johnson, AG\& Triger, DR.(1989) Anorectal varices, haemorrhoids, and portal hypertension. Lancet, Feb, Vol.18, Nos.1(8634), pp.249-352.(ISSN 01406736)

Ito, K; Shiraki, K; Sakai T; Yoshimura, H \& Nakano T.(2005) Portal hypertensive colopathy in patients with liver cirrhosis. World J Gastroenterol., May, Vol.11, Nos.20, pp.31273130.( ISSN 1007-9327)

Izsak, EM \& Finlay, JM. (1980).Colonic varices. Three case reports and review of the literature. Am J Gastroenterol.; Feb, Vol.73, Nos.2, pp.131-136. (ISSN 0002-9270)

Jacobs, DM; Bubrick, MP; Onstad, GR \& Hitchcock, CR. (1980).The relationship of hemorrhoids to portal hypertension. Dis Colon Rectum, Nov-Dec, Vol.23, Nos.8, pp.567-569.(ISSN 1530-0358)

Kozarek, RA; Botoman, VA; Bredfeldt, JE;Roach, JM; Patterson, DJ \& Ball, TJ. (1991). Portal colopathy: prospective study in patients with portal hypertension. Gastroenterology, Nov, Vol. 101, Nos. 5, pp.1192-1197.(ISSN 0016-5085)

McCormack, TT; Sims, J; Eyre-Brook, I. et al. (1985). Lesions in Portal hypertension: Inflammatory gastritis or congestive gastropathy?. Gut, Nov, Vol. 26, Nos 11, pp. 1226-1232. (ISSN 0017-5749)

Misra, SP; Dwivedi, M; Misra, V; Agarwal, SK; Gupta, R; Gupta, SC \& Mittal, VP. (1990). Endoscopic and histological appearance of gastric mucosa in patients with portal hypertension. Gastrointestinal Endoscopy, Nov-Dec, Vol. 36, Nos 6, pp. 575-579.(ISSN 0016 5107)

Misra, SP; Dwivedi, M \& Misra, V. (1996). Prevalence and factors influencing hemorrhoids, anorectal varices and colopathy in patients with portal hypertension. Endoscopy, May, Vol. 28, Nos.4, pp.340 -345. .(ISSN 0013-726X) 
Misra, SP; Misra, V \& Dwivedi, M. (1999). Effect of oesophageal variceal sclerotherapy on hemorrhoids, anorectal varices and portal colopathy. Endoscopy, Nov., Vol.31, Nos 9, pp.741-744. .(ISSN0013-726X)

Misra, SP; Misra, V \& Dwivedi, M.(2002). Effect of esophageal band ligation on hemorrhoids, anorectal varices and portal hypertensive colopathy. Endoscopy, Mar., Vol.34, Nos.3, pp.195-198. .(ISSN 0013-726X)

Misra, V; Misra, SP;Dwivedi, M \& Gupta, SC. (1997). Histomorphometric study of portal hypertensive enteropathy. American Journal of Clinical Pathology, Dec, Vol. 108, Nos 6, pp. 652-7.(ISSN 0002- 9173)

Misra, V; Misra, SP\& Dwivedi, M. (1998). Thickened gastric mucosal capillary wall: a histological marker for portal hypertension. Pathology, Feb, Vol.30, Nos 1, pp. 1013.(ISSN 0031-2025)

Misra, V; Misra, SP; Dwivedi, M; Singh, PA \& Kumar, V. (2003) Colonic mucosa in patients with portal hypertension. J Gastroenterol Hepatol, MarVol.18, Nos 3, pp.302-8. (ISSN: 0815-9319).

Naveau, S; Leger-Ravet, MB; Houdayer, C; et al.(1995) . Nonhereditary colonic angiodysplasias. Dig. Dis. Sci. Apr, Vol. 40, Nos 4, pp. 839-842.(ISSN 0163 2116)

Papazian, A; Braillon, A; Dupas, JL; Sevvent, F\& Capron, JP. (1986) .Portal hypertensive gastric mucosa: an endoscopic study. Gut, Oct, Vol. 27, Nos10, pp. 1199-1203. (ISSN 0017-5749)

Rabinovitz, M; Zajko, AB; et al.(1990). Diagnostic value of brush cytology in the diagnosis of bile duct carcinoma: a study in 65 patients with bile duct strictures .Hepatology, Oct, Vol.12, Nos.4, pp.747-752.(ISSN 1527 3350)

Sarfeh, IJ \& Tarnawaski, A. (1987) .Gastric mucosal vasculopathy in portal hypertension. Gastroenterology, Nov, Vol.93, Nos 5, pp. 1129-1131.(ISSN 0016-5085)

Scandalis, N; Archimandritis, A; et al., (1994). Colon findings in cirrhotics with portal hypertension. A prospective colonoscopic and histological study. J. Clin. Gastroenterol. Jun, Vol. 18(4), pp.325-328. (ISSN 0192-0970)

Sharma, R \& Gorbein, MJ. ( 1995) .Angiodysplasia and lower gastrointestinal tract bleeding in elderly patients. Arch.Intern. Med, April24, Vol. 155(8), pp.807-812.(ISSN 0003-9926)

Tarnawski, A; Sarfeh, IJ; Stachura, J et al. (1988). Microvascular abnormalities of the portal hypertensive gastric mucosa. Hepatology, Nov-Dec, Vol.8(6), pp. 1488-1494. (ISSN $15273350)$

Triger, D; Hosking, S. (1989) .The gastric mucosa in portal hypertension.J. Hepatol., Mar, Vol. 8(2), pp.267-272. ( ISSN 1527 3350)

Thiruvengadam, R \& Gostout, CJ. (1989) . Congestive gastroenteropathy: An extension of nonvariceal upper gastrointestinal bleeding in portal hypertension. Gastrointest Endosc., Vol. 35(6), pp, 504-507. (ISSN 0016 5107)

Viggiano, TR \& Gostout, CJ. (1992). Portal hypertensive intestinal vasculopathy: a review of the clinical, endoscopic andhistopathological features. Am. J. Gastroenterol., Vol. 87(8), pp.944-954.(ISSN 0002-9270)

Weinshel, E; Chen, W; Falkenstein, DB; Kessler, R \& Raicht, RF. (1986) Hemorrhoids or rectal varices: defining the cause of massive rectal hemorrhage in patients with portal hypertension. Gastroenterology., Vol.90, Nos.3, pp.744-747 .(ISSN 0016-5085)

Yoshie K, Fujita Y, Moriya A, Kawana I, Miyamoto K, Umemura S. (2001)Octreotide for severe acute bleeding from portal hypertensive colopathy: a case report. Eur J Gastroenterol Hepatol, Vo.13, Nos.9, pp.1111-1113. (ISSN 0954 691X) 


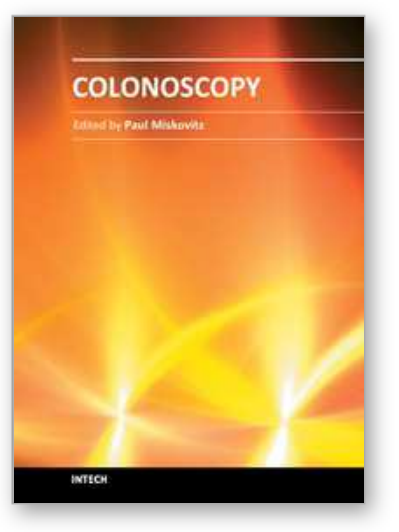

\author{
Colonoscopy \\ Edited by Prof. Paul Miskovitz
}

ISBN 978-953-307-568-6

Hard cover, 326 pages

Publisher InTech

Published online 29, August, 2011

Published in print edition August, 2011

To publish a book on colonoscopy suitable for an international medical audience, drawing upon the expertise and talents of many outstanding world-wide clinicians, is a daunting task. New developments in videocolonoscope instruments, procedural technique, patient selection and preparation, and moderate sedation and monitoring are being made and reported daily in both the medical and the lay press. Just as over the last several decades colonoscopy has largely supplanted the use of barium enema x-ray study of the colon, new developments in gastrointestinal imaging such as computerized tomographic colonography and video transmitted capsule study of the colonic lumen and new discoveries in cellular and molecular biology that may facilitate the early detection of colon cancer, colon polyps and other gastrointestinal pathology threaten to relegate the role of screening colonoscopy to the side lines of medical practice. This book draws on the talents of renowned physicians who convey a sense of the history, the present state-of-the art and ongoing confronting issues, and the predicted future of this discipline.

\title{
How to reference
}

In order to correctly reference this scholarly work, feel free to copy and paste the following:

Vatsala Misra, Vishal Dhingra, S P Misra and Manisha Dwivedi (2011). Portal Hypertensive Colopathy, Colonoscopy, Prof. Paul Miskovitz (Ed.), ISBN: 978-953-307-568-6, InTech, Available from: http://www.intechopen.com/books/colonoscopy/portal-hypertensive-colopathy

\section{INTECH}

open science | open minds

\section{InTech Europe}

University Campus STeP Ri

Slavka Krautzeka 83/A

51000 Rijeka, Croatia

Phone: +385 (51) 770447

Fax: +385 (51) 686166

www.intechopen.com

\section{InTech China}

Unit 405, Office Block, Hotel Equatorial Shanghai

No.65, Yan An Road (West), Shanghai, 200040, China 中国上海市延安西路65号上海国际贵都大饭店办公楼 405 单元 Phone: +86-21-62489820

Fax: $+86-21-62489821$ 
(C) 2011 The Author(s). Licensee IntechOpen. This chapter is distributed under the terms of the Creative Commons Attribution-NonCommercialShareAlike-3.0 License, which permits use, distribution and reproduction for non-commercial purposes, provided the original is properly cited and derivative works building on this content are distributed under the same license. 